\title{
Análisis de los factores condicionantes del impacto de los microcréditos en el empoderamiento de la mujer senegalesa
}

\section{Determining factors of microcredit impact on Senegalese women's empowerment}

\section{Soledad Gutiérrez Pastor}

Doctoranda. Université Gaston Berger, Saint Louis. Senegal

eloss80@hotmail.com

\section{José Ángel Aznar Sánchez}

Profesor Titular. Universidad de Almería. España

jaznar@ual.es

\section{RESUMEN}

Los microcréditos son un instrumento financiero concebido para contribuir a dar una oportunidad a los pobres y, fundamentalmente, a las mujeres. Con su ayuda, las mujeres pueden iniciar o ampliar una actividad económica que tiene un impacto positivo en diferentes ámbitos socioeconómicos y en su nivel de empoderamiento. No obstante, este empoderamiento viene condicionado por el entorno en el que la mujer desarrolla su actividad económica, social y vital. En este trabajo se analiza el impacto que la concesión de los microcréditos ha tenido en el nivel de empoderamiento de las mujeres senegalesas. A partir de los discursos obtenidos de los principales implicados mediante la realización de entrevistas en profundidad y grupos de discusión en la ciudad de Saint Louis, se evalúan los factores que condicionan su impacto.

\section{ABSTRACT}

Microfinance is thought of as an economic instrument which can open an opportunity to poor people, especially women. Thanks to microcredits, women can set up or follow an economic activity with a positive impact on diverse socioeconomic aspects and on their empowerment. However, such empowerment is invariably conditioned by the environment in which women carry out their economic and social activities, as well as their lives. This study analyses the microcredit impact on women's empowerment in Senegal. Based on the in-depth interviews with the main actors involved and discussion groups in Saint Louis, the determining factors of the microcredit impact are assessed.

PALABRAS CLAVE

microcréditos | empoderamiento | mujer | Senegal | factores condicionantes

KEYWO RDS

microcredits | empowerment | women | Senegal | determining factors

\section{Introducción}

Desde hace varias décadas, los estudiosos del desarrollo tenían la hipótesis de que para mejorar las condiciones de vida y reducir los niveles de pobreza en el mundo era fundamental tener acceso a los recursos financieros. Ante el reto de diseñar productos financieros inclusivos y adaptados a las necesidades de la población marginada de los circuitos formales, que carecía de garantías crediticias, avales y de un historial de rendimiento bancario, en la década de los setenta del pasado siglo surgieron los microcréditos. Este instrumento financiero nació con el claro objetivo de aumentar y mejorar el acceso de la población más pobre del mundo a sistemas de pequeños préstamos. Se trataba de reducir al mínimo las restricciones que afrontan los pobres en sus intentos por acceder al crédito y poder así luchar contra su situación de pobreza (Lacalle 2001). Gracias a este acceso al crédito se ha contribuido no solo a la reducción de la pobreza, también a lo que se conoce como "círculos virtuosos" de empoderamiento económico, mayor bienestar y empoderamiento social y político para sus beneficiarios (Mayoux y Hartl 2009).

Los resultados que se comenzaron a obtener a partir de las diferentes experiencias en la concesión de microcréditos fueron muy positivos, puesto que no sólo contribuían a mejorar la situación económica de los beneficiarios, sino que además generaban efectos sociales positivos, como el fortalecimiento de las mujeres y nuevas relaciones más igualitarias entre los dos sexos. Las potencialidades de esta herramienta 
son tales que se ha llegado a plantear el acceso al crédito como un derecho humano fundamental, ya que si se prestara dinero a los pobres y se fomentasen una serie de principios financieros sensatos, se podría acabar con la pobreza en el mundo (Yunus 2005).

No obstante, algunos autores como Buckley (1997) comenzaron a cuestionar si los microcréditos realmente podían llegar a resolver el problema de la pobreza en el mundo. Aquellos que critican al movimiento a favor de los microcréditos han planteado varias dudas respecto a la efectividad del modelo en términos absolutos y consideran que se está sobrestimando su papel como herramienta para erradicar la pobreza (Martínez 2008). Entre los argumentos esgrimidos destaca el que apunta a que hay muy poco trabajo de investigación que muestre el impacto de los microcréditos y que apunte a la causalidad (Nagore 2007).

Existen estudios que analizan el impacto de los microcréditos en diferentes países del África Subsahariana y en diferentes ámbitos como la salud, la alimentación, la educación, el trabajo infantil, el hogar, la cohesión social y el empoderamiento (García y Díaz 2011, Van Rooyen y otros 2012, Lacalle y otros 2008). Sin embargo, en estos estudios el análisis de los niveles de empoderamiento de la mujer se limita a utilizar indicadores de empoderamiento tales como el número de matrículas en educación primaria y secundaria, el porcentaje de mujeres que acaban la educación primaria, el porcentaje de población femenina económicamente activa, etc. (Calero 2010). Estas aproximaciones recogen de manera limitada e indirecta el impacto real que la concesión de un microcrédito tiene en el nivel de empoderamiento real de una mujer.

El objetivo general de este trabajo es analizar el impacto que la concesión de un microcrédito ha tenido en el nivel de empoderamiento de la mujer senegalesa, tratando de mostrar los condicionantes derivados del entorno y de estos cuatro factores específicos. Para ello se ha realizado un amplio trabajo de campo con los principales implicados durante dos años. Y la aproximación al nivel de empoderamiento de la mujer también resulta diferente a la habitual, en el sentido de que recogemos la propia perspectiva de las mujeres que han recibido un microcrédito. Se trata, por tanto, de dar valor a la realidad tal y como ellas la perciben, haciendo hincapié en sus ideas, sentimientos, percepciones y los motivos y creencias que las llevan a actuar y tomar decisiones, así como los posibles cambios que el microcrédito ha provocado.

Entendemos que para estudiar el impacto que los microcréditos tienen sobre la población beneficiaria se deben tener presentes las influencias, la cultura, el entorno y la tradición a la que están sujetas estas personas. Los resultados no sólo dependerán de su utilización sino que estarán sometidos a una serie de condicionantes. Las necesidades concretas de financiación de la población objetivo, el alcance de sus propuestas y la estrategia que se decida adoptar, son algunos de los criterios que marcarán el modelo microfinanciero más adecuado (García 2012). Cortés (2009) da un paso más en esta consideración al concretar que hay cuatro factores específicos que destacan por encima de los demás: ámbito geográfico; género; religión, casta y etnicidad; y nivel de pobreza.

\section{Ámbito geográfico}

Cuando una institución microfinanciera (IMF) diseña un determinado producto o servicio debe tener muy en cuenta si los clientes residen en zonas urbanas o rurales, ya que los niveles de desarrollo y las actividades que se realizan presentan características diferentes, como los costes de transacción, el analfabetismo, las infraestructuras existentes, la concentración de la población o la presión social ejercida.

\section{Género}

Hablar de género en las microfinanzas implica hablar del enfoque hacia las mujeres como clientes. La pobreza afecta en mayor medida a las mujeres. Éstas son más vulnerables y la estructura patriarcal de muchas de las sociedades en las que viven las relega al plano del hogar, donde no pueden decidir sobre el destino de los ingresos económicos en el seno familiar. Esta situación acrecienta su exclusión financiera y el recelo de las instituciones a concederles financiación.

Armendáriz y Roome (2008) ofrecen cuatro razones por las que las mujeres son mejores clientes de microcréditos que los hombres: sus tasas de reembolso son mayores (las mujeres son más reacias al riesgo y más conservadoras en su estrategia de inversión); son más susceptibles a la presión de sus iguales y más sensibles ante la amenaza de humillación pública; reducen los gastos de funcionamiento del banco porque son más puntuales en los pagos; y son más eficientes en la concesión y reembolso de los préstamos. 
La tradición religiosa, la etnia o la casta a la que pertenezcan los potenciales clientes también constituyen un elemento a tener en cuenta en la definición y desarrollo de productos y servicios microfinancieros. Otra de las barreras que es fundamental superar es la del idioma, directamente relacionada con la etnia a la que pertenezcan los beneficiarios. Las IMF deben comunicarse en el mismo idioma que hablen sus clientes, ya que muchos de los que viven en zonas rurales no utilizan la lengua oficial del país, sino dialectos locales.

\section{Nivel de pobreza}

Desde sus inicios, las microfinanzas han tenido la pretensión de dirigirse a los segmentos más pobres de la población. No obstante, en la mayoría de los países hay muchas personas que carecen de acceso a los servicios financieros tradicionales, desde los más pobres entre los pobres, económicamente inactivos en muchas ocasiones, hasta pequeños empresarios que tampoco son aceptados en los circuitos formales de financiación.

\section{Metodología}

El trabajo de campo se ha desarrollado durante los años 2012 y 2013 en la ciudad de Saint Louis, al norte de Senegal. La labor de obtención de información ha tenido lugar en los barrios más pobres de la ciudad en los que desarrollaban su actividad las entidades que han colaborado en esta investigación. Se da la circunstancia que uno de estos barrios, Guet N'Dar, es el que tiene la mayor densidad de población de África Occidental. Y se ha trabajado en tres proyectos en los que los microcréditos eran su eje fundamental: el de la Unión de Mujeres Transformadoras de Pescado de Guet N'Dar a través de la ONG española Fundación Habitáfrica; el de la Asociación Jigeen ak Jigeen con la colaboración de la asociación española Entre Mujeres; y el de la Asociación de Niños y Jóvenes Trabajadores de Saint Louis cuya contraparte española es la Fundación Xaley.

A la hora de seleccionar la muestra decidimos optar por una estrategia de muestreo que facilitara la heterogeneidad y la accesibilidad de los casos. Así, entre las mujeres interesadas en participar en la investigación se ha realizado una preselección valorando las siguientes características: diversidad en cuanto a la antigüedad del proyecto, variedad de actividades emprendidas, continuidad en el programa (solicitud de más de un crédito), éxito y fracaso del negocio, diferentes edades y variedad de estado civil. Con la intención de cubrir un número suficiente de casos que nos permitiera aplicar criterios de saturación teórica, aplicamos también la técnica de la bola de nieve, mediante la cual todas las entrevistadas pudieron dar información que condujo a seleccionar a nuevas participantes. En el caso de los informantes clave su selección se ha realizado de manera intencional según su representación en la comunidad o en grupos de interés para la investigación. El resultado del amplio trabajo de campo desarrollado es que se ha podido contar con un total de 71 personas, de las que 51 son mujeres pertenecientes a los tres proyectos de microcréditos indicados, además de 20 informantes clave (1), cuya información aportada ha permitido alcanzar la saturación teórica (2), al objeto de poder realizar aportaciones con base sólida.

Los instrumentos de recogida de información primaria utilizados han sido la entrevista en profundidad, la observación participante y los grupos de discusión, que en todos los casos han sido transcritos intentando garantizar el máximo rigor y analizados de forma inmediata (3). Como secuencia lógica, la información obtenida y procesada ha llevado a la identificación de una serie de códigos que se encuentran agrupados en cuatro niveles de empoderamiento: individual (4), familiar (5), comunitario (6) y económico (7), así como en las perspectivas de futuro.

La metodología cualitativa de la investigación ha permitido obtener datos descriptivos a partir de las propias palabras de las mujeres y de su conducta observada y ha facilitado el trabajo a través de un diseño flexible que nos ha ayudado a entender los casos objeto de estudio en el plano individual y como parte de un todo, encuadrándolos en su contexto natural de desarrollo e intentando comprender a las personas dentro de su realidad. Partiendo de esta base, no se ha buscado generalizar en las conclusiones, sino comprender, de forma detallada, las perspectivas de estas mujeres en su lucha por empoderarse (percibida o no como tal), procurando humanizar el proceso de estudio, de modo que las conclusiones reflejaran sus sentimientos y percepciones y un conocimiento profundo de su situación personal, sin buscar una explicación basada en 
planteamientos estadísticos que nos alejarían de este propósito.

\section{Resultados}

Con la intención de evaluar los cambios que han generado en las mujeres la obtención de un microcrédito, en primer lugar, presentamos la situación de partida de estas mujeres. En segundo lugar, exponemos los principales cambios que se han producido en su vida a partir de la obtención de los microcréditos. Y en tercer lugar, estudiamos de manera más detenida la influencia del entorno sociocultural y la religión.

\subsection{La situación de partida de las mujeres y su acercamiento a los programas de microcréditos}

A partir de las entrevistas realizadas hemos podido conocer que la mayor parte de las beneficiarias de los programas de microcréditos solicitó la financiación para mejorar laboralmente. Los principales destinos del dinero obtenido han sido las inversiones en una actividad que ya realizaban o para abrir un taller. Especialmente en el caso de Guet N'Dar donde las mujeres ya transformaban el pescado antes de la llegada del proyecto, pero no contaban con los recursos suficientes para la compra de materia prima ni para ampliar la actividad.

"Pedí el crédito para trabajar bien porque a veces sale del mar una gran cantidad de pescado y si las vendedoras o las personas que transforman el pescado, si no tienen dinero para comprar el pescado, sería difícil y con el crédito podemos comprar una gran cantidad de pescado, transformarla o venderla". B7.

"Pedí el crédito porque tenía en la cabeza que un día quería abrir una mercería, una tienda donde trabajar. Porque al principio compraba y vendía, pero era muy difícil ir de una casa a otra para vender y luego hay personas que se quedan con la mercancía dos o tres meses sin pagar, por eso pedí el microcrédito". B15.

El caso de Guet N'Dar es especialmente significativo para explicar cómo los microcréditos han ayudado a estas mujeres a hacer frente a la usura. Uno de los motivos que esgrimen para solicitar el préstamo es la necesidad que tenían de hacer frente a la feroz competencia, especialmente de los comerciantes, que las extorsionaban vendiéndoles la materia prima por un elevado precio y después comprándosela transformada dejándoles un escaso margen de beneficios. Antes de contar con el microcrédito, muchos pescadores no se atrevían a vender directamente a las mujeres porque desconfiaban de su capacidad para pagarles. Por tanto, el crédito les ha servido para convertirse en microempresarias, contar con financiación propia y negociar directamente con los pescadores, sin necesidad de empeñar su trabajo a usureros.

"Un problema que me pasó un día es que estaba en un periodo del primer crédito. Un día quise comprar pescado, una cantidad de pescado y el vendedor no me quería vender porque en aquel tiempo yo no tenía dinero. Y le dije al vendedor: 'yo te pagaré'. Y este último respondió: '¿cómo me vas a pagar y con qué dinero? No confío en ti'. Yo le juré que: 'mañana, por la mañana o por la tarde, te pagaré'. Y este vendedor me dio el pescado. Al día siguiente al mediodía me presenté en el lugar para entregar a este vendedor el dinero. Cuando empecé a contar los billetes, éste último abrió los ojos, porque pensaba que era una mujer mentirosa y desde aquel día este vendedor tuvo una gran confianza en mí. Soy una mujer respetable, trabajadora, muy honesta. Y todo eso es gracias a los microcréditos". B1.

"La Mutua es una buena cosa porque ayuda mucho, porque la mutua es muy cercana. Es diferente a antes, cuando tenía que comprar pescado, teníamos la competición con las otras mujeres y otros hombres, por ejemplo, que tienen los medios para comprar el pescado. Nosotras ahora tenemos la posibilidad de hacer competencia a los hombres y a otros operadores, eso es una buena cosa que valoramos mucho". Presidenta UFT.

Incluso en ocasiones, otras mujeres compañeras actuaban como intermediarias financieras practicando la usura, como fue el caso de la presidenta del grupo de mujeres transformadoras de pescado.

"Al principio no había un sistema de microcréditos lo que suponía un problema con las mujeres. No sé si has conocido a la señora (Presidenta) que tenía el monopolio del poder en Guet N'Dar. Todo lo que decía, se hacía. Porque tenía dinero. Así que las mujeres, cuando no tenían dinero para comprar el 
producto, era ella la que financiaba. ¿Entiendes? Era ella la que financiaba. Todo el tiempo las tenía como esclavas. Estaban obligadas a ir donde (Presidenta) porque era ella la que les podía ayudar en lo que necesitaban. Ahora, con el sistema de microcréditos, esto ha cambiado. Las mujeres son más autónomas que antes. (La Presidenta) aún mantiene el poder pero no como antes, porque antes, si organizábamos una reunión y (la Presidenta) no estaba presente, no podíamos movilizar a las mujeres. Pero ahora, de hecho, es lo contrario. Por lo que esto ha contribuido mucho en el cambio de las mujeres". Técnico Eje Pesca CDIG.

Otra importante representación ha valorado la relevancia de recibir los microcréditos para realizar tareas que posteriormente les permiten ayudar financieramente a sus familias y colaborar en los gastos del hogar o en la escolarización de los hijos, especialmente cuando el cabeza de familia no aporta dinero suficiente.

"Entré en los microcréditos porque había visto la situación de mi marido, que era pobre, un pescador que no tenía ni una piragua, ni una máquina, es difícil tener un beneficio en la pesca (...). Así hablé con las españolas y recibí el crédito para mejorar la situación de mi familia". B8.

"Quería mejorar mi condición de vida y ayudar a mi familia porque sabía que había mucha gente en la casa y había pocas personas que trabajaban y pedir un crédito y trabajar y sacar beneficio (...) ayudaría mucho en la familia. Otro motivo es que después de la muerte de mi hermano, éste contribuía mucho en la casa, murió y dejó a sus hijos, muchos de sus hijos aquí, hacía falta trabajar para mantenerlos". B12.

Muchas beneficiarias consideraron que si no hubiesen tenido microcréditos se habrían visto obligadas a quedarse en casa sin trabajar, o que hubiesen podido hacerlo pero con mucho más esfuerzo y con menos garantías de éxito.

"Si no tuviera el crédito no podría trabajar, porque esta suma de dinero nadie de mi familia me lo podría haber dado o un amigo. El microcrédito me ha permitido trabajar y ganarme la vida". B22.

"Si no hubiéramos recibido un microcrédito nos quedaríamos en casa sin hacer nada (...). Nuestras vidas serían muy duras si no tuviésemos financiación”. GD4.

A través de estos testimonios observamos la oportunidad laboral que los microcréditos han supuesto para las mujeres. Poder salir de sus casas y desarrollar una actividad generadora de beneficios les permite apoyar económicamente a la familia y sobrepasar el histórico rol reproductivo que las tenía ancladas al hogar.

\subsection{Los cambios generados a partir de la obtención de microcréditos}

Las transformaciones que las mujeres han experimentado después de formar parte de los programas de microcréditos no se reducen solamente a los percibidos como tales sino que tienen otras implicaciones sobre su individualidad, su situación familiar y su relación con la comunidad.

"Los microcréditos son una cosa muy importante, es una maravilla. Bailo para celebrarlo, porque estoy trabajando, ganando dinero. Mi vida de ahora es muy diferente de la vida que llevaba antes". GD3.

Además, les han dado la posibilidad de tener cierta independencia económica, lo que les motiva y les permite ampliar sus planes futuros, hacer las cosas que antes querían pero no podían. Así, poder ayudar a sus familias y alcanzar sus metas (como cubrir los gastos de estudios de sus hijos e hijas, o los de los padres), contribuye a mejorar la confianza que estas mujeres tienen en sus posibilidades.

"Antes no me atrevía a llevar a mis hijos para que recibieran clases particulares, pero con los microcréditos tuve la decisión de llevar a mi hija Anta y pagar por ella cada fin de mes 5.000 y eso es dinero del crédito (...). Esta idea la he tenido cuando entré en los microcréditos. Porque al principio no era fácil, vivía en condiciones muy difíciles, pero si una persona quiere cambiar, poco a poco va a cambiar, con los microcréditos veo un futuro mejor". B8.

"Mi vida ha cambiado mucho, porque con mi trabajo mantengo a mi familia. Hay muchos gastos aquí en la casa y soy yo la que lo arreglo, participo en la educación de mis hijos y cuando uno está enfermo también con los medicamentos, participo yo, así que puedo decir que los créditos han cambiado mucho mi vida". B14. 
A un nivel puramente económico encontramos que el aumento de ingresos ha generado una serie de mejoras en las vidas de las mujeres en cuanto a la inversión en alimentación, remodelación del hogar, asistencia sanitaria, formación profesional y en la economía familiar. Aunque estos cambios no han ocurrido de forma unánime en todas las beneficiarias, observamos que la mayoría de ellas reconocen los impactos positivos de los microcréditos. Sin embargo, también resulta de interés detenerse en los casos negativos en cada uno de estos ámbitos por ampliar y complementar la perspectiva comprensiva.

\section{Vivienda}

En ningún caso se ha informado de un empeoramiento en el estado de la vivienda, si bien conviene insistir en que la situación de partida de la misma ya se reconoce mala. Se trata de casas viejas, en mal estado, con un espacio insuficiente, problemas de goteras y ausencia de canalización de aguas.

Partiendo de esta realidad, la progresión lógica es que si ha habido inversiones en las infraestructuras, las casas hayan mejorado. Efectivamente, trece mujeres han hecho alguna inversión en sus hogares frente a once que han destinado el dinero a otros asuntos. Algunas han optado por comprar un terreno para la construcción de una vivienda nueva.

"Desde que recibí el crédito, mi vida ha cambiado y llego a hacer muchas cosas, por ejemplo, he construido una pared en mi casa, de ladrillos, porque antes podía estar en la calle y ver todo lo que había en la casa". B13.

"A mí los microcréditos me han ayudado. He comprado un terreno en Dakar. Esto gracias al ahorro de los microcréditos. Si no hubiera tenido un crédito, nunca hubiera llegado a comprar un terreno". GD3.

\section{Formación}

La mayoría de las entrevistadas han mejorado su formación desde que forman parte de los programas de microcréditos. Este progreso se debe a que algunas son analfabetas y otras tan sólo han cursado la enseñanza obligatoria. Sin embargo, todos los proyectos que hemos estudiado cuentan con un importante componente formativo. En unos se han impartido clases de alfabetización y contabilidad básica; y en otros se han centrado en las formaciones orientadas a la mejora profesional. Cursos de tintura de telas, marketing, elaboración de jabón, costura, bordado, transformación de cereal local, salud e higiene en el trabajo, informática o microjardinería, han ayudado a orientar su vocación hacia la obtención de un empleo.

"Los microcréditos son una cosa estupenda para las mujeres, sobre todo las de este barrio. Han ayudado en muchos temas y las formaciones que recibimos también, el bordado, la tintura, la informática, la alfabetización, eso forma parte del desarrollo de un barrio o el desarrollo de un país, porque cuando las mujeres se activan, trabajan para ayudar a los hombres, el desarrollo se nota". B11.

"Desde que entré en los microcréditos mi vida ha cambiado mucho. Antes quería hacer muchas cosas, pero no tenía ni la formación ni la capacidad para hacerlo. He recibido muchas formaciones que me permiten dirigir o hacer muchas cosas". B12.

Tan sólo tres mujeres no reconocen cambios a nivel educativo puesto que decidieron libremente no participar en las formaciones que, aunque recomendables, no siempre son obligatorias para obtener un microcrédito.

\section{Salud}

Entre las catorce mujeres que han constatado una mejora en su salud se encuentran las que reciben la visita semanal de una enfermera y medicamentos, como parte del programa de microcréditos de la Asociación Jigeen ak Jigeen; y las que afirman sentirse mejor desde que trabajan, puesto que el dinamismo les da ánimos a nivel físico y emocional.

"Sabemos que aquí en Senegal hay muchas personas, siempre hemos vivido con la crisis, muchas personas que están enfermas, no pueden acudir al dispensario porque no tienen dinero para comprar pastillas. Aquí en la sede hay pastillas gratis y eso gracias a los españoles". B12.

Otras siete mujeres consideran que su salud es la misma que antes de comenzar a trabajar y tres creen que 
ha empeorado debido a que ahora tienen más trabajo o a los achaques propios de la edad.

\section{Alimentación}

Preguntadas por la alimentación, diecinueve mujeres informaron que tanto ellas como sus familias están bien alimentadas. La comida no es muy variada y se basa esencialmente en arroz, pan, verduras cocinadas, pollo y pescado seco. La carne de cordero se reserva para las fiestas. La utilización de sal y azúcar en la preparación es elevada lo que influye en los índices de glucemia, colesterol e hipertensión. Otras cinco mujeres consideran que la alimentación en el hogar es deficiente, aún así ha mejorado en los últimos años.

De todas ellas, dos tercios han podido invertir parte de sus beneficios en mejorar las comidas. Esto es, esencialmente, poder comprar más cantidad de comida y aumentar el consumo de carne. Un problema ajeno a la capacidad económica es el desconocimiento de la pirámide nutricional y de hábitos de consumo saludables. La Asociación Jigeen ak Jigeen ha ofrecido algunas charlas informativas sobre nutrición pero sus costumbres culinarias están más arraigadas.

"Cuando recibí el crédito y compre el frigorífico, si preparo por ejemplo una comida que es mucho, come el resto o antes de comer guardo una parte en el frigorífico. Antes no podía. Todos los restos los echaba en la basura. Eso es un avance". B10.

"Desde que recibí el crédito mi vida ha cambiado bien, porque con los beneficios que tengo mejoro la alimentación en la casa". B11.

\section{Economía familiar}

Nuevamente, dos tercios de las mujeres participantes en el estudio han contabilizado mejoras en la economía familiar desde que perciben microcréditos. Los beneficios obtenidos por sus trabajos, aunque no sean elevados, han tenido como destino principal el bienestar de la familia, unas veces como fuente principal de ingresos y otras como complementos a los salarios de otros miembros.

"La ventaja de un crédito es que con el dinero yo puedo trabajar y cada vez devolver a la mutua una parte o con otra parte puedo abrirme una cuenta propia con la cual, en el futuro, cuando no hay crédito o si tengo un problema, podré usar de este beneficio para resolver mi problema. Eso es el beneficio del microcrédito". GD1.

Siete mujeres no han experimentado ningún cambio. Tres son chicas jóvenes, en cuyos hogares son otras las personas que aportan los ingresos principales y de ellas una no trabaja actualmente debido a que su negocio no fructificó. Las cuatro restantes ya ejercían con anterioridad su trabajo en la transformación de pescado $\mathrm{y}$, aunque los microcréditos les han facilitado la compra de materia prima, el elevado número de miembros de la familia de los que son responsables y la estacionalidad de la pesca no les han permitido percibir una mejora significativa en el último año. De éstas, una padece una enfermedad que la incapacita para trabajar y desde hace varios meses no ejerce su profesión.

La única persona que ha informado de un empeoramiento en su economía es una mujer que transforma pescado, pero que en el momento de la entrevista llevaba varios meses con muy poco trabajo por culpa de la escasez en la pesca, por lo que puntualizó que desde mediados del año 2012 sus ingresos habían disminuido.

\subsection{La influencia del entorno sociocultural y la religión}

El mero hecho de recibir una cantidad de dinero no implica empoderamiento, ni siquiera en un nivel estrictamente económico. Cuando hablamos de microcréditos como herramienta de empoderamiento de la mujer no estamos afirmando que por sí solos conduzcan directamente a un aumento de poder de las beneficiarias. De hecho, sería erróneo pensar que sin más acciones, y simplemente por el hecho de recibir una cantidad determinada de dinero, se activa de forma automática el empoderamiento (Batliwala 1997). Todo lo contrario, si la concesión de un microcrédito no va debidamente acompañada de otras acciones complementarias y de un seguimiento adecuado de cada caso, puede convertirse en un instrumento de presión financiera sobre las personas que tienen más dificultades para hacer frente a los reembolsos y que para conseguirlo pueden llegar a recurrir a familiares, amigos o prestamistas informales. En otros casos, no 
devolver el microcrédito supone una deuda no sólo económica, sino también social y el descrédito personal dentro de la comunidad.

La contribución de las microfinanzas por sí solas puede ser muy limitada en el caso de las mujeres más pobres y desfavorecidas (Mayoux y Hartl 2009). El contexto, el nivel sociocultural, el mercado, etc., son factores que influyen en la capacidad de hombres y mujeres de emprender un negocio y generar beneficios. Por este motivo y, para conceder a cada nivel el protagonismo que merece, nuestro análisis se ha centrado en las realidades individual, familiar, comunitaria y económica de modo que podamos apreciar los cambios reales sobre la mujer en los diferentes aspectos de sus vidas.

Consideramos que si el incremento económico estaba acompañado de un aumento de poder en estos ámbitos de su vida cotidiana, podríamos percibir más claramente los efectos que los microcréditos tienen sobre el empoderamiento femenino. Los principales problemas de las mujeres senegalesas que viven en el medio rural están relacionados con la pobreza y se deben a la escasa alfabetización, enfermedades no tratadas, dificultad de acceso al crédito, desiguales derechos en la práctica y posición de subordinación debido a la tradición y la religión.

"El principal problema de la mujer senegalesa, al igual que del resto de la sociedad del país, es enfrentarse a la pobreza, que cada vez es más importante, porque afecta a la mayoría de la población, entre la que se encuentra la mujer. Vivimos en un sistema patriarcal que hace a las mujeres más vulnerables. La pobreza también afecta a las mujeres en otros aspectos, como la salud, la salud reproductiva, la educación, la gestión del poder en los asuntos públicos (...). De manera general la pobreza afecta a toda la población senegalesa, pero más específicamente a la mujer, porque está ligada a una cuestión demográfica y de cultura, que está marcada por el patriarcado que hace de la mujer una persona dominada y que no tiene los recursos de poder necesarios para cambiar esta tendencia. Pero gracias a la aplicación de la ley (de la paridad) estamos intentando cambiar la mentalidad (...). A nivel de la gestión del poder, la religión y la tradición pueden suponer un problema, por el peso del patriarcado, pero creo que cada vez más la mentalidad está cambiando, sobre todo en el caso del empoderamiento económico de las mujeres. Después de los cambios estructurales, los hombres han perdido mucho poder económico y las mujeres han comenzado a ocupar ese espacio. La mentalidad está evolucionando y hoy día está muy bien aceptado que las mujeres tengan actividades económicas muy desarrolladas". Presidenta del Consejo Senegalés de Mujeres (COSEF).

"Las mujeres tienen la voluntad de aprender y de trabajar pero el problema de las mujeres senegalesas es el problema de la independencia, no son independientes, seguimos dependiendo de los maridos, de nuestros padres y eso es un obstáculo. Una mujer que recibe una formación muy importante, va a hacer la formación, tendrá conocimiento pero a la hora de ganar dinero y de reembolsar, sería difícil porque pensará en su familia (...). Constituye un obstáculo para el avance de las mujeres cuando dicen que la mujer debe estar detrás del hombre, la mujer no debe hacer ciertas cosas, eso frena el desarrollo de la mujer. Las mujeres deben aprender, cambiar de conocimiento, tener una cultura, abrirse a los otros y no decir que esto lo prohíbe la religión, hay cosas que dicen y que no existen en el Corán". Formadora.

Los microcréditos pueden utilizarse como una herramienta de empoderamiento siempre y cuando estén adaptados a la realidad del entorno y vayan debidamente acompañados de otras medidas de apoyo ya que por sí solos no manifiestan la fuerza suficiente para promover el empoderamiento real de la mujer en los cuatro niveles analizados.

Uno de nuestros objetivos principales a la hora de plantear este trabajo ha sido llegar a una definición consensuada sobre el significado que el empoderamiento tiene para las mujeres senegalesas que viven en el ámbito rural y que tienen dificultades de financiación. Este consenso ha sido prácticamente unánime entre nuestros entrevistados al considerar que, efectivamente, los microcréditos han apoyado el proceso de empoderamiento de las mujeres.

"La financiación da poder y en el barrio los hombres respetan más a las mujeres, porque si no tuvieran esta financiación se quedarían en sus casas para hacer las tareas domésticas o quedarse debajo de los árboles para hablar de tonterías, pero si tienen un trabajo, una financiación, se dedican a hacer cosas productivas". Delegado de barrio.

"Los microcréditos son un instrumento de desarrollo que permite a muchas personas que están 
excluidas participar en el circuito de la producción y salir de la situación de pobreza. Hoy, las mujeres que tienen capacidad de tener dinero están mejor consideradas en sus hogares tanto por el marido como por el resto de la familia. Les permite crear o consolidar microempresas. Les permite tener una mejor posición en la sociedad, tener dignidad, solucionar las necesidades diarias, la comida, la escolarización de los hijos. Los microcréditos permiten hacer frente a las necesidades y no quedarse en la calle poniendo la mano. (...). Yo digo que la mujer que tiene la posibilidad de hacerse cargo de la familia es mucho más respetada por todo el mundo, incluso por el marido. Las mujeres están mostrando su coraje en el desarrollo socioeconómico. La mentalidad ha cambiado y los microcréditos dan poder y ese poder ha cambiado la mentalidad". Presidenta de mutua de ahorro y crédito.

No obstante, no podemos obviar los efectos que este aumento de poder tiene sobre mujeres que históricamente han vivido en una sociedad patriarcal, y donde la religión les recomienda la sumisión hacia sus padres y maridos. En este contexto, pretender un cambio radical inmediato puede generar desavenencias en el seno familiar y estigmatizar a la mujer en su comunidad. Se trata del coste social que implica el empoderamiento y que puede variar desde conflictos con el marido, que se puede sentir amenazado por una pérdida de protagonismo y poder; el rechazo de la comunidad, que puede interpretar en la nueva conducta de la mujer un distanciamiento de la norma social establecida; o no cumplir con los dictados religiosos, al no mostrar sumisión, lo que a su vez puede ser interpretado como falta de respeto. Ante estas amenazas sería comprensible identificar en las mujeres comportamientos que perpetúen las desigualdades históricas como respuesta al miedo de sufrir rechazo. De hecho, si las acciones conducentes al aumento de poder no se realizan de manera consciente, consensuada y voluntaria, pueden derivar en conflictos de intereses y confusión sobre los nuevos roles.

"Para mí participa en promover la independencia de la mujer pero forzosamente habrá efectos negativos. Por ejemplo, hay mujeres ricas que se divorcian. Entonces, si la mujer tiene dinero y ya no respeta (8) a su marido, tu marido dice que no y tú lo contrario, eso les va a traer problemas con su religión. Si tenemos en cuenta a las mujeres intelectuales, la mayor parte se quedan solteras, eso es porque tienen dinero y porque son intelectuales y esto hace que los hombres les tengan miedo. La mayor parte de las mujeres inteligentes llegan a ser independientes económicamente. Porque no es muy compatible y hay que elegir entre estudiar, ser independiente económicamente o casarse. La mayor parte de las mujeres doctorandas en la universidad están solteras. Esto a la larga puede ser un impacto negativo de la autonomía financiera de las mujeres. Si tomas el ejemplo de España y de otros países árabes no musulmanes, la mujer que es intelectual e independiente económicamente no se casa. Aquí es costumbre que los hombres prefieran a mujeres rurales, es decir, amas de casa que se quedan en el hogar, que sean tranquilas. El hombre necesita sentirse que es hombre, que es dominante, sea cual sea su naturaleza, el hombre siempre tiene necesidad de sentirse superior a la mujer. Físicamente se sienten más fuertes y moralmente sienten la necesidad de imponerse a la mujer y nosotras debemos cada vez más decir que no (...). Los maridos no quieren que se inculquen ideas que puedan hacer que sus mujeres se revolucionen y se vuelvan contra ellos. Por eso los microcréditos tienen un aspecto positivo que les da a las mujeres otras perspectivas de la vida pero también puede tener un aspecto negativo en relación a la vida familiar y en pareja". Técnica1 ONG.

"Por un lado, las microfinanzas pueden ayudar al empoderamiento de la mujer porque la mujer que tiene un punto de partida puede crear actividades generadoras de beneficios y con ello no sólo no te quedas en la casa estresada sino que tienes una ocupación y te liberas cada vez más y esto es un aspecto positivo. Otro aspecto negativo es que la mujer que no hace nada es sumisa a su marido y se queda en su casa atendiendo a su marido y sus hijos. Una vez que tiene una ocupación, el tiempo que le dedica a su marido disminuye y eso puede suponer una fuente de conflictos (9), aunque la mujer no tenga esa intención". Técnica2 ONG.

Entonces, si la religión y la sociedad ejercen esta influencia tan determinante sobre las libertades femeninas, ¿podremos esperar que se alcance con éxito el nivel de poder deseado? El siguiente testimonio nos advierte de que una mujer que sigue los dictados de su religión, aunque estudie y tenga un empleo bien remunerado, nunca podrá empoderarse totalmente.

"Si aplicamos el Corán, nunca se empoderará, será muy difícil. Los microcréditos pueden reforzar un poco, pueden mejorar la situación de la mujer, pero ésta nunca estará totalmente empoderada. Ciertas categorias de mujeres que son completamente dependientes de sus maridos y que son sumisas, los microcréditos pueden ayudarlas a estar más empoderadas. En relación a los aspectos religiosos, los 
microcréditos no pueden hacer nada. En el aspecto financiero podemos clasificar a las mujeres en diferentes categorías. La categoría de las mujeres que están obligadas, que son sumisas por obligación, son dependientes de sus maridos, son sus maridos los que lo pagan todo y están obligadas a ser sumisas por el aspecto financiero. Pero si tienen una actividad generadora de beneficios, se van a sentir más activas y habrá ciertas cosas que no estén dispuestas a aceptar. Por ejemplo, si yo me incluyo en una categoría, en mi categoría el microcrédito no podrá cambiar nada en relación a la sumisión". Técnica2 ONG.

En la base del empoderamiento está la necesidad de reconocer que se trata en todos los casos de grupos heterogéneos y que, por tanto, no existe una fórmula universal que lo garantice. Incluso en caso de alcanzarse, resultaría tremendamente arriesgado (e incluso inútil) intentar calcularlo como si de un fenómeno cuantitativo se tratase. ¿Deberíamos medirlo según una escala que nos indique el porcentaje necesario de empoderamiento que se recomienda alcanzar? ¿Podemos afirmar, sin miedo a equivocarnos, que una persona está empoderada cuando ha alcanzado un cierto nivel en su vida? Por ello nuestra propuesta se ha centrado en estudiar los procesos generadores de empoderamiento y las repercusiones que tienen en las personas, en tanto que individuos autónomos y como miembros de una comunidad. De hecho, el empoderamiento puede ser experimentado por individuos solos o agrupados, organizaciones y comunidades geográficas enteras (Zimmerman 2000). Batliwala (1997: 193) entiende el empoderamiento como:

"Una redistribución del poder, ya sea entre naciones, clases, razas, castas, géneros o individuos. Las metas del empoderamiento de las mujeres son desafiar la ideología patriarcal, transformar las estructuras e instituciones que refuerzan y perpetúan la discriminación de género y la desigualdad social (la familia, la raza, la clase, la religión, los procesos educativos y las instituciones, los sistemas y prácticas de salud, las leyes y los códigos civiles, los procesos políticos, los modelos de desarrollo y las instituciones gubernamentales) y capacitar a las mujeres pobres para que logren acceso y control de la información y de los recursos materiales. De esta manera, el proceso de empoderamiento tiene que aplicarse a todas las estructuras y fuentes de poder relevantes".

A esta definición añadimos el matiz de la libertad de expresión, tal y como han expresado nuestras entrevistadas.

"Para mí significa la libertad de expresión de la mujer, la promoción de la feminidad, la paridad de género. Para mí todo eso es un deseo de libre expresión. Y cuando decimos expresión hacemos referencia a los hombres. Un hombre puede decir lo que piensa, dice lo que quiere, porque antes ha reflexionado. La mujer tiene la facultad de reflexionar como el hombre, de pensar bien las cosas como el hombre. Así que para mí el empoderamiento no es otra cosa que la libre expresión para todas las personas". Técnica1 ONG.

Y la valoración de la mujer en todos sus sectores de actuación, reconociendo su papel tanto en el ámbito reproductivo como en el productivo.

"El empoderamiento de la mujer es su capacidad para hacerse cargo de liberar las presiones sociales, culturales y económicas. Se trata de la capacidad de las mujeres de disponer de su cuerpo y todos sus derechos". Experto universitario en género.

"Para mí el empoderamiento es el reconocimiento de la mujer como colega, como socia, como madre". Técnica2 ONG.

El entorno juega un papel determinante. No podemos caer en la tentación de diseñar programas de financiación en base al éxito que hayan tenido experiencias previas en otros lugares del mundo. La historia, las tradiciones, el modelo de sociedad, las leyes del país y las creencias influyen sobremanera en el desarrollo de la población. Las características propias de cada grupo y zona y "las tradiciones e historias locales desempeñan un papel como mínimo tan importante como el de la 'lógica novedosa' de los micropréstamos en cada caso" (Nágera de Sousa 2008: 16).

Es imprescindible que las beneficiarias sientan que la financiación está destinada a ayudarlas a resolver sus problemas y alcanzar sus objetivos en la vida. Que las condiciones se adaptan a sus necesidades y que son respetuosas con sus creencias y sus situaciones personales. Las tradiciones y la religión influyen de tal 
manera en las beneficiarias que los efectos de los microcréditos dependen en gran medida de ellas.

En cuanto a los principales cambios en los que los microcréditos, junto a otras herramientas, han tenido un impacto más notable según el estudio que hemos realizado encontramos que se trata de aspectos relacionados con cuestiones humanas, es decir, que dependen de la voluntad de cada uno, como por ejemplo las mejoras en la formación, en el aspecto físico, el rol de la mujer en el hogar (sigue siendo la responsable de las tareas domésticas pero como ahora aporta dinero comienza a tener más respeto de los otros miembros y opina en la toma de decisiones), la creación de redes sociales, la participación en la comunidad y las inversiones en salud, entre otros.

En cambio, el impacto de los microcréditos es menos significativo cuando se trata de moldear actitudes prefijadas por la religión, como es el caso del rol del hombre en el hogar (sigue sin participar en las tareas y actúa como jefe de familia tomando las principales decisiones); la consideración de la maternidad como forma de realización femenina; el matrimonio y la necesidad de estar unida a un hombre; la sexualidad, que sigue siendo una cuestión tabú; la toma de decisiones en el hogar (en manos de los hombres, principalmente); la aceptación de la poligamia; la elección de la enseñanza coránica por delante de la educación formal; la igualdad/desigualdad entre hombre y mujer, marcada por la sumisión de ellas; y la dicotomía entre la obtención de logros gracias a los méritos propios o al destino y los designios divinos. Sin ser el objetivo de los microcréditos impactar sobre las creencias y conductas basadas en la religión, sí se ha constatado que éstas ejercen una fuerte presión sobre el rol de la mujer. Entonces, no se trataría de pretender cambiar esos principios, puesto que podría suponer el rechazo social a quien se aparta de la tradición, sino de adaptar las herramientas al contexto y trabajar a partir de los objetivos de los beneficiarios.

Cuando nuestro análisis comenzó a desvelar la posibilidad de que los microcréditos podían influir, en mayor medida, sobre los asuntos humanos y menos en los divinos quisimos, debatir esta idea junto a las mujeres en los grupos de discusión que confirmaron nuestras hipótesis, al igual que el imán entrevistado.

"Las cosas divinas se dejan en manos de Dios, pero las otras cosas las mujeres pueden reivindicar muchas cosas y estar en sitios más altos que los hombres". GD3.

"No lo vamos a aceptar, con algunas condiciones para cambiar algunas cosas de nuestra religión, nunca lo vamos a cambiar". GD4.

"Una persona que ha recibido una buena educación en la religión nunca cambiará aunque sea rica. Pero hay algunas personas que empiezan a cambiar de manera de hablar, de manera de hacer las cosas si empiezan a enriquecerse". Imán y marabout.

Sin embargo también hemos encontrado elementos que nos hacen atisbar un cambio de ideas y comportamientos que se está gestando en la sociedad y, aunque la religión sigue ejerciendo una férrea influencia, la pobreza y las necesidades imponen poco a poco nuevos modelos de comportamiento.

"Eso lo dice el Corán pero nadie lo sigue, el mundo ha evolucionado. Las mujeres demandan la paridad. Aunque el Corán lo diga, el Profeta dijo que la mujer tiene sus derechos, tiene derecho de trabajar, derecho de progresar económicamente y que hay que poner a la mujer delante porque su propia mujer era muy rica, ése es el verdadero problema, quien quiere ponerla detrás". Presidenta de mutua de ahorro y crédito.

En definitiva, hemos agrupado los impactos de los microcréditos y nos han dado como resultado que, en cuestiones que las beneficiarias consideran de dominio individual, pueden esforzarse para intentar mejorarlas. En cambio, cuando están convencidas de que deben salvaguardar actitudes que les recomienda o impone su religión, como la actitud de sumisión hacia el marido, aseguran no estar dispuestas a cambiarlas aunque los objetivos de los proyectos de microfinanzas, las ONG o las IMF se lo aconsejen, ya que para ellas es primordial ser una buena musulmana, aunque eso implique tener menos poder (económico o personal).

En el caso de los microcréditos, hemos constatado que resulta más fructífero e interesante conocer las historias de vida de sus protagonistas, y reflexionar junto a ellas sobre cómo esta herramienta les ha influido y si realmente han alcanzado los objetivos que perseguían al solicitarlo. Consideramos que promover el 
empoderamiento de la mujer debe entenderse como un todo integrado que combine estrategias a diferentes niveles. Nuestra propuesta se basa en la adaptación al contexto de realización y, a partir de ahí, la identificación de la estructura social dominante, y el reconocimiento y consenso de las iniciativas a poner en marcha junto a la comunidad.

\section{Conclusiones}

Mucho se ha hablado y documentado sobre los múltiples beneficios de conceder microcréditos a mujeres en situación de vulnerabilidad económica. Entre otros, encontramos una mayor inversión en los gastos del hogar, alimentación, educación de los hijos y las hijas, además de su buen historial de reembolso. Es decir, ayudando a una mujer, se mejora el bienestar de toda su familia. Aunque la mayoría de los estudios también apuntaban a un progreso en el nivel de empoderamiento de la mujer al recibir un microcrédito, muy pocos han abordado esta cuestión de manera específica y directa.

Aprehender si ha tenido lugar, o no, una mejora en el nivel de empoderamiento es una tarea compleja puesto que se trata de un proceso endógeno de adquisición y/o aumento de poder que coloca al individuo como eje central del proceso, y promotor de su propio desarrollo y el de su comunidad. Sin embargo, todo individuo está influenciado por una cultura, tradiciones, creencias, relaciones y motivaciones, y los procesos de empoderamiento deben surgir a partir del reconocimiento de esta realidad y la confianza en las capacidades y habilidades del ser humano.

En el contexto senegalés estudiado hemos observado la importancia de las tradiciones y la religión musulmana que actúan como condicionantes en el desarrollo de los individuos y muy especialmente de la mujer. La sumisión, la prevalencia del hombre como jefe del hogar y la subordinación de la mujer al rol reproductivo deben ser tenidos en cuenta al abordar el empoderamiento. Aunque desde un punto de vista occidentalista pueda parecer un signo de retraso, debemos entender y respetar el hecho de que muchas mujeres no están dispuestas a enfrentarse a su religión ni a su comunidad para alcanzar unos niveles de desarrollo que no consideran que estén en consonancia con sus objetivos vitales. Así pues, aunque las estructuras patriarcales de poder y la supremacía masculina condicionen el papel de la mujer en la sociedad, los microcréditos deben saber adaptarse a estas realidades $y$, en su caso, ayudar a transformarlas en función de las metas que cada persona se marque y en consenso con su comunidad. No se trataría, en todo caso, de imponer uno y otro modelo de empoderamiento en función de lo que se ha alcanzado en otras partes del mundo. Como hemos defendido, no existe una fórmula universal que mida el aumento de poder o que asegure alcanzarlo. Los objetivos, los fines e incluso los medios deben ser planteados individualmente y estar adaptados al contexto. Las ambiciones de una mujer europea no tienen por qué coincidir con las de una africana, ni siquiera dentro del mismo continente, país o región son las mismas. Estamos ante un proceso endógeno, individual o colectivo, que en cualquier caso cede el protagonismo a las intenciones personales y que, por tanto, debe ser legitimado como tal, en cuanto que cuenta con un importante componente subjetivo y de aspiraciones propias. Podemos considerar que una persona o su comunidad están empoderadas en función de su participación y logros sociales, pero es su sentimiento de avance y desarrollo el que realmente nos podrá ofrecer una idea de cómo ha mejorado su vida. Y en este contexto, el microcrédito es tan solo un instrumento más para facilitar el proceso, aunque con unas posibilidades que pueden multiplicar los efectos de otras acciones.

\section{Notas}

1. En la presentación de los resultados hemos codificado los nombres de modo que los informantes clave aparecen identificados por su responsabilidad laboral o técnica y las mujeres beneficiarias con la letra $B$ seguida de un número según el orden en el que fueron entrevistadas. Los grupos de discusión se señalan como GD más el número de cada grupo en función del orden en el que fueron realizados.

2. Se consideró que los datos se habían saturado cuando se compararon entre sí los testimonios recogidos 
y generaron una serie de códigos de análisis, hasta que dejaron de aportar información nueva.

3. Las entrevistadas se expresaron en su lengua común, el wolof, y de forma simultánea los discursos fueron traducidos al español por una profesional local. Las expresiones propias de la lengua fueron interpretadas intentando mantener la fidelidad con su sentido original. Durante la transcripción se mantuvo la literalidad de lo recogido, manteniendo el argot, las expresiones y el léxico jergal del informante a partir de la traducción literal de sus palabras (Arjona y Checa 1998).

4. El nivel individual parte desde la propia persona, la mujer en este caso, y se centra en aspectos relacionados con la percepción que tiene de sus problemas y posibilidades, de la mejora de la autoestima y la confianza en sí misma. El microcrédito puede darle la seguridad económica que le ayude a mejorar sus perspectivas de futuro.

5. Dentro del hogar, el aumento de poder por parte de la mujer resulta más perceptible en cuanto a la toma de decisiones. Gracias a los ingresos generados en el negocio emprendido, la mujer comienza a posicionarse cada vez más como principal sustentadora del hogar o, al menos, aporta un importante complemento a la economía familiar. Esto favorece que pueda decidir sobre el destino de ese dinero, invirtiéndolo en el bienestar familiar, la educación de los hijos, alimentación y salud, reduciendo su propia vulnerabilidad y la de sus allegados. En estos casos, la adquisición de poder por parte de la mujer se enfrenta a las estructuras de dominación patriarcal tradicional y supone un aliciente para instaurar un nuevo orden social en el que predomine un equilibrio de poderes.

6. Las mujeres, conscientes de su aporte al bienestar familiar, pueden mejorar su confianza y valía personales. Si los programas de microcréditos van acompañados de acciones paralelas, como formaciones, sensibilizaciones, refuerzo institucional y de grupo, acceso a la sanidad y la escolarización, etc., tanto de las propias mujeres como de su entorno, podremos percibir con más claridad los efectos positivos sobre su confianza y habilidades personales. El aumento de los conocimientos y la formación de redes de apoyo a través de actividades grupales, así como el acceso al mercado de trabajo pueden ayudar a mejorar las condiciones en las que se desenvuelven las mujeres de una comunidad (Mayoux y Hartl 2009).

7. Acceder a determinadas cantidades de dinero que permitan la puesta en marcha y gestión de una actividad empresarial puede mejorar los ingresos propios, pero no siempre implica un mayor control de los beneficios, ya que estos pueden estar gestionados por una figura masculina.

8. El término "respeto" se refiere aquí a cuestiones morales y éticas relacionadas por una parte con la disminución o ausencia del miedo que la mujer siente hacia su marido y que podría causarle complejo de inferioridad por sentirse imposibilitada a alcanzar sus metas. Por otro lado, hace referencia al reconocimiento de su autonomía como individuo y en la autodeterminación que marca las relaciones y las opciones individuales de las que dispone. Una vez que la mujer cuenta con medios económicos para ser independiente, se reduce su dependencia del marido y, por tanto, no tiene tantos motivos para temerle. Es decir, no se trata tanto de no reconocer la valía masculina, sino de mejorar la confianza en la propia.

9. Aunque sería interesante poder mostrar con etnografía si ha habido conflictos o no, divorcios, etc., en las entrevistas que hemos realizado no se ha ofrecido ese nivel de detalle. Hay que tener presente que estas mujeres no son muy dadas a airear los problemas familiares y tienden a encubrirlos. En todo caso, en ningún momento se ha declarado que el acceso a los microcréditos haya provocado divorcios. Entre las beneficiarias sólo había una divorciada y ya lo estaba antes de entrar en el programa de microcréditos.

\section{Bibliografía}

Arjona Garrido, Ángeles (y Juan Carlos Checa Olmos)

1998 "Las historias de vida como método de acercamiento a la realidad social", Gazeta de Antropología, n 14, artículo 10.

http://hdl.handle.net/10481/7548

Armendáriz, Beatriz (y Nigel Roome) 
2008 "Empowering women via microfinance in fragile states", Université Libre de Bruxelles, Working Papers CEB 08-001.

Batliwala, Srilatha

1997 "El significado del empoderamiento de las mujeres: nuevos conceptos desde la acción", en Magdalena León, Poder y empoderamiento de las mujeres. Santa Fe de Bogotá, T/M Editores: 187-211.

Buckey, Graeme

1997 "Microfinance in Africa: is it either the problem or the solution?", World Development, $\mathrm{n}^{\circ} 27$ (1): 1081 1093.

Calero Serrano, Josefa

2010 Microfinanzas, microcréditos y género en Senegal. Madrid, Fundación IDEAS para el Progreso.

Cortés García, Francisco Joaquín

2009 Finanzas éticas: banca ética, microfinanzas y monedas sociales. Almería, La Hidra de Lerna.

García Pinar, Raquel

2012 "Microcréditos, pobreza y género: consideraciones generales para la elaboración de programas de desarrollo vinculados a las microfinanzas con enfoque de género", Revista de Microfinanzas y Banca Social, $\mathrm{n}^{\circ}$ 1: 91-114.

García Rodríguez, Francisco Javier (y Yolanda Díaz Perdomo)

2011 "Los microcréditos como herramienta de desarrollo: revisión teórica y propuesta piloto para el África

Subsahariana", CIRIEC-España, Revista de Economía Pública, Social y Cooperativa, nº 70: 101-126.

Lacalle Calderón, Maricruz

2001 "Los microcréditos: un nuevo instrumento de financiación para luchar contra la pobreza", Revista de Economía Mundial, $\mathrm{n}^{\circ}$ 5: 121-138.

Lacalle Calderón, Maricruz (y otros)

2008 "Estudio piloto de evaluación de impacto del programa de microcréditos de Cruz Roja española en Ruanda", Revista de Economía Mundial, nº 19: 83-104.

Martínez Castillo, Alberto David

2008 "El microcrédito como instrumento para el alivio de la pobreza: ventajas y limitaciones", Cuadernos de Desarrollo Rural, nº 5 (61): 93-110.

Mayoux, Linda (y Maria Hartl)

2009 Género y microfinanciación rural: cobertura y empoderamiento para las mujeres. Roma, FIDA.

Nágera de Sousa Peixera, Tony

2008 "Los microcréditos en la cooperación internacional. Una forma simbólica de legitimación social de la 'doxa' económica”, Gazeta de Antropología, n 24 (2), artículo 44.

http://hdl.handle.net/10481/6968

Nagore, Leandro

2007 “¿Pueden los microcréditos solucionar la pobreza mundial?, Revista Papeles, n 99: 167-175.

Van Rooyen, Carina (y otros)

2012 "The impact of microfinance in Sub-Saharan Africa: a systematic review of the evidence", World Development, $\mathrm{n}^{\circ} 40$ (11): 2249-2262.

Yunus, Muhammad

2005 El banquero de los pobres: los microcréditos y la batalla contra la pobreza en el mundo. Barcelona, Paidós lbérica. 
psychology. New York, Kluwer: 43-s. 